\title{
OS ANIMAIS NOS DESENHOS DAS CRIANÇAS: UM PANORAMA SOBRE AS PESQUISAS QUE INVESTIGAM A REPRESENTAÇÃO DE ANIMAIS NA INFÂNCIA
}

\author{
ANIMALS IN CHILDREN'S DRAWINGS: A PANORAMA ON RESEARCHES THAT \\ INVESTIGATE THE REPRESENTATION OF ANIMALS IN CHILDHOOD
}

Sheila Alves de Almeida ${ }^{1}$

ORCID iD: 0000-0002-2030-5173

Giselle Barbosa Andrade Rodrigues ${ }^{2}$

ORCID iD: $\underline{0000-0001-9926-9402}$

\section{RESUMO}

Esta pesquisa tem como objetivo apresentar um panorama da produção de artigos, dissertações e teses cujo instrumento metodológico se fundamenta nos desenhos das crianças sobre animais. Para tanto, foi realizada uma revisão bibliográfica na área de ensino de ciências nos últimos 12 anos. Os critérios para a seleção dos estudos foram: pesquisas envolvendo sujeitos de 3 a 11 anos de idade; pesquisas cujo instrumento metodológico fosse o desenho; pesquisas na área de ciências com o objetivo de investigar a representação de animais pelas crianças. Em seguida, foram identificados os recursos metodológicos, os espaços de produção das pesquisas e como são analisadas as representações das crianças nos desenhos. Por fim, considera-se que os autores se restringiram à observação de aspectos morfológicos dos animais e não aos aspectos cognitivos e psicológicos do desenho infantil. O conceito de representação é entendido como uma relação de semelhança entre os aspectos morfológicos dos animais e a imagem que as crianças apresentam deles nos desenhos.

Palavras chave: Revisão bibliográfica. Ensino de Ciências. Desenho infantil. Animais.

\begin{abstract}
This research aims to present an overview of the production of articles, dissertations and theses whose methodological instrument is based on children's drawings about animals. To this end, a bibliographic review was carried out in the area of science education in the last 12 years. The criteria for selecting the studies were: research involving subjects from 3 to 11 years old; research whose methodological instrument was drawing; research in the area of science with the aim of investigating the representation of animals by children. Then, the methodological resources, the research production spaces and how the children's representations in the drawings are analyzed were identified. Finally, it is considered that the authors were restricted to the observation of morphological aspects of animals and not to the cognitive and psychological aspects of children's drawing. The concept of representation is understood as a relationship of similarity between the morphological aspects of animals and the image that children present of them in the drawings.
\end{abstract}

Keywords: Bibliographic review. Science Teaching. Children's drawing. Animals.

\footnotetext{
${ }^{1}$ Doutora em Educação pela Universidade de São Paulo (USP). Professora Associada da Universidade Federal de Ouro Preto (UFOP - Instituto de Ciências Exatas e Biológicas (ICEB). Programa de Pós- Graduação em Educação da UFOP (PPGE-UFOP). E-mail: sheilaalvez@ufop.edu.br.

${ }^{2}$ Mestre em Educação pela Universidade Federal de Ouro Preto (PPGE-UFOP) - Licenciada em Pedagogia pela Universidade Federal de Ouro Preto (UFOP). E-mail: GiselleBARodrigues@ hotmail.com.
} 


\section{INTRODUÇÃO}

Desde muito pequenas, antes mesmo de ingressarem na escola, as crianças já apresentam conhecimentos sobre o mundo natural: observam os seres vivos, interagem com eles, encantam-se com o pulo dos grilos, o canto da cigarra, o passeio das abelhas pelas flores, o voo da borboleta, as cores das joaninhas, as pequenas formigas que andam em fileiras e vivem em colônias A construção do conceito de ser vivo nasce dessas experiências. Tal conceito é fundamental para organizar as percepções do mundo em que vivemos.

A esse respeito, destacam-se os estudos de Piaget, ao ampliar as investigações acerca das formas de raciocínio das crianças sobre os seres vivos e os processos biológicos (MARTÍ, 2012). As pesquisas de Piaget demonstram que as crianças apresentam níveis fixos e hierárquicos de pensamento. Em relação à noção de vida, esse autor estabelece quatro níveis distintos e sucessivos: nível I (crianças até 6 anos) - noção de que é vivo tudo que tem atividade, função ou utilidade; nível II (crianças de 6 a 8 anos) - é vivo tudo que se movimenta; nível III (crianças de 8 a 12 anos) - é vivo o que tem movimento próprio; nível IV (a partir de 11/12 anos) - são vivos apenas os animais e as plantas (PIAGET, 1926).

Já Costa-Neto (2000) traz uma compilação de pesquisas realizadas no Nordeste brasileiro acerca dos usos e percepções humanas dos insetos. Segundo ele, as diversidades morfológicas e ecológicas causaram e causam impactos na cultura humana, influenciando a língua e a literatura; as artes plásticas, gráficas, cênicas e musicais; a culinária; a medicina; o lazer; a religião e superstições de culturas tradicionais ou não.

A propósito, nos anos 2000, um caso particular de uma menina de 7 anos se tornou conhecido mundialmente, quando ela e um entomólogo profissional publicaram um artigo sobre como as meninas interagem com os insetos, reflexo das informações que circulam nas redes sociais (JACKSON \& SPENCER 2017). Essa história tem início em 25 de agosto de 2016, quando a Sociedade Entomológica do Canadá recebeu um e-mail de Nicole Spencer explicando que sua filha de 7 anos apresentava muito interesse por insetos e entomologia, o que levava colegas a provocarem-na rotineiramente. Spencer desejava incentivar os interesses de sua filha e reverter as intimidações que ela sofria na escola por gostar de insetos. Em sua mensagem, procurava informações de contato com um entomologista profissional que pudesse responder a algumas das perguntas de sua filha. A mensagem do pai de Sophia foi encaminhada a um entomólogo que divulgou as perguntas da menina nas redes sociais e disponibilizou 
informações sobre os insetos. Tais informações suscitaram a curiosidade e o diálogo entre outras meninas revertendo o "bullying" que Sophia sofria por gostar desses animais. Após a criação do tweet \# bugsgirls, o envolvimento das crianças e adultos, mediado pelas informações disponibilizadas, foi registrado em um artigo por Jackson e Sophia (JACKSON \& SPENCER 2017).

Outra experiência interessante foi citada por Medioli (2017), ao publicar, em sua coluna de jornal, suas recordações de infância quando capturava formigas em vidros de maionese. Chamavam-lhe a atenção, os corpos das formigas, seus movimentos. Observava fascinada as formigas se alimentando, cavando túneis, ovos que despontavam e larvas transparentes. Mediolli (2017) lembra que à noite levava o vidro para o quarto e, em vez de ler livros, observava as formigas.

Por sua vez, Wallon e colaboradores (1990), ao investigar desenhos de crianças indianas, observaram que elas reproduziram um esquema gráfico cultural ao desenhar homens e animais. Os animais estão presentes nos mais diversos tipos de ambientes da Terra, compartilhando dos mesmos espaços que os seres humanos, mantendo sempre uma relação direta ou indireta com eles (ALMEIDA, et. al, 2019).

Não sem razão, o estudo dos animais é parte integrante do currículo de Ciências. Aliás, levar as crianças a observar os animais e seus modos de vida é uma estratégia para introduzilas na linguagem das ciências. Aliados à observação, muitos projetos de ensino de ciências propõem o desenho como estratégia para o desenvolvimento da temática dos animais. Os Parâmetros Curriculares Nacionais (PCN, 1997) indicam a importância do ensino sobre os animais e ambientes em que vivem. Enfatizam os PCN que a capacidade de narrar das crianças ou descrever um fato é enriquecida pelo desenho ao levar, progressivamente, a criança a incorporar detalhes do objeto ou do fenômeno observado. O desenho é, assim, uma possibilidade de registro de observações, além de um instrumento de informação da própria Ciência (PCN, p. 45. 1997).

Assim, dada a importância da representação de animais pelas crianças, o presente artigo objetiva apresentar um panorama da literatura sobre os desenhos infantis. Aliás, as representações de animais nos desenhos infantis têm sido objeto deste estudo há algum tempo (RODRIGUES \& ALMEIDA, 2017 e RODRIGUES, 2019).

Considera-se, pois que as pesquisas e experiências contribuem para a reflexão sobre os desenhos dos animais na infância, haja vista que a elaboração gráfica pela criança é fundamental 
para o seu desenvolvimento. Assim, este trabalho tem como propósito analisar algumas pesquisas que utilizam os desenhos das crianças sobre animais para compreender a função deles nas investigações em ciências.

\section{REFERÊNCIAL TEÓRICO}

\subsection{Desenho como sistema de representação}

A palavra representação tem vários significados. Michaeles ${ }^{3}$ assim a define: "imagem ou ideia que traduz nossa concepção de alguma coisa ou do mundo; ato pelo qual se faz vir à mente a ideia ou o conceito correspondente a um objeto que se encontra no inconsciente." Já Aurélio $^{4}$ acrescenta que essa palavra é oriunda do latim representatione e como significado tornar presente, tendo no latim clássico, sua utilidade apenas para objetos, sem ter relações com pessoas. E o Dicionário Básico de Filosofia ${ }^{5}$ indica que o conceito de representação geralmente define-se por analogia com a visão e com o ato de formar uma imagem de algo, tratando-se no caso de uma "imagem não-sensível, não-visual". Destaca, ainda que, sob vários aspectos, a relação de representação parece problemática, sendo, por vezes, entendida como uma relação causal entre o objeto externo e a consciência; por vezes, como uma relação de correspondência ou semelhança. A principal dificuldade parece ser o pressuposto de que a consciência seria incapaz de apreender diretamente o objeto externo.

Por sua vez, André Giordan e Gérard de Vecchi (apud WORTMANN, 2001) apresentam estudos importantes para o desenvolvimento de trabalhos científicos, utilizando o termo representação com diferentes sentidos. Esses autores citam cerca de trinta significados dessa palavra, que vão de pré-representação remanescente até a de pré-requisito. Dessa forma, segundo os autores, o conceito de representação tende a ser um conceito frouxo, com sua definição difusa. E, como se vê, há multiplicidade de significados dessa palavra, logo diferentes sentidos que cada falante e/ou autor atribui a ela. Por conseguinte, Giordan e Gérard de Vecchi (apud WORTMANN, 2001) procuraram, em suas investigações sobre representações, entender como se processa a cognição pelo acompanhamento da evolução das ideias perante um assunto

\footnotetext{
MICHAELIS: moderno dicionário da língua portuguesa. São Paulo: Companhia Melhoramentos, 1998(Dicionários Michaelis). 2259p.

${ }^{4}$ FERREIRA, Aurélio Buarque de Holanda. Miniaurélio: o dicionário da língua portuguesa. Curitiba: Positivo, 2010.

${ }^{5}$ JAPIASSU, H. \& MARCONDES, D. Dicionário Básico de Filosofia. Editora Zahar. Rio de Janeiro, 2001.
} 
e, assim, as implicações diretas em ações educativas, focalizando as dimensões cognitivas da aprendizagem.

De outro modo, Stuart Wall (1997) define representações como algo que envolve pensar o significado que está no objeto, pessoa, ideia ou evento real. Para esse autor, a linguagem da representação funciona pela imitação da verdade que está estabelecida no mundo. Destaca, também, que a representação está ligada à cultura do sujeito e, ainda, que essa cultura está diretamente ligada aos significados partilhados. Ainda segundo Wall (1997), a linguagem é um sistema de representação do qual fazemos uso de símbolos e sinais, tais como: sons, palavras escritas, fotografias, desenhos animados, músicas, desenhos e até objetos. Os símbolos podem representar, de acordo com a cultura, conceitos, ideias e sentimentos.

Destacam Laburú e colaboradores (2013) que, conforme Vygotsky, na história da evolução da espécie humana, a utilização de marcas externas acabou por se transformar em processos internos de mediação, passando o homem a utilizar signos internos, isto é, representações mentais que substituem os objetos do mundo real (LABURÚ, et. al, 2013 p. 10). Os autores chamam a atenção para a necessidade de ultrapassar os limites da linguagem oral e escrita na aquisição dos conceitos na sala de aula. Ressaltam, ainda, que a formação de conceitos científicos ocorre por meio de combinações de uma variedade de representações semióticas.

Em adição, afirmam Laburú e colaboradores (2013) que toda representação é cognitivamente parcial em relação ao que representa e não é semelhante na maneira de ver e compreender um mesmo conteúdo conceitual. De acordo com esses autores, a aprendizagem resultante da das diversas formas representacionais constitui um mecanismo pedagógico fundamental para aprimorar o processo de significação e variadas interpretações e entendimento do conceito, fenômeno ou objeto estudado. A compreensão de um mesmo conceito fundado em distintas linguagens por coordenação de suas múltiplas representações e integração multimodal faz com que o pensamento e os achados científicos abram possibilidades de nova significação conceitual (LABURÚ, et. al, 2013 p. 10). Assim, para que a aprendizagem se realize é necessário que os estudantes sejam desafiados a desenvolver um entendimento mais profundo dos significados em diversas representações. Para isso acontecer, diferentes linguagens devem ser trabalhadas na sala de aula e os estudantes precisam ser capazes de transformar e coordenar as representações. 
Representação para Piaget (1978, apud PILLAR, 1996) é a capacidade de se lembrar, diante de uma imagem ou signo, o objeto que não está presente, ou o ato não realizado, embora o pensamento não se reduza apenas às imagens, ele também se constrói por elas. Para ele, a imagem será um significante, e o conceito, o significado, e o pensar interligarão as significações. Dessa forma, dois sentidos para o termo de representação são construídos e se relacionam entre si. O primeiro, mais amplo, se apoia num sistema de conceitos; e o segundo, mais restrito, são as lembranças simbólicas da realidade. De acordo com Piaget (1978), a representação demanda que a criança tenha condições de construir novos esquemas e reformular estruturas para entender o que as estruturas do período sensório-motor não conseguiram, pois nesse estágio a criança não apresenta condições de estabelecer novas diferenciações e representações, ou seja, no estágio, sensório motor a criança apenas interage com os objetos e só mais tarde enriquece sua interação mediante a representação dos objetos ausentes.

Em síntese, Piaget (1978 p.345) ressalta que representar é reconstruir, no plano mental, o que estava apenas estruturado no campo das ações. Portanto, pode-se afirmar que há representações quando há imitações do objeto que está ausente e que ela se inicia quando há, simultaneamente, diferenciação e coordenação entre os significantes e significados/significações.

Desse modo, ao desenhar, a criança constrói conhecimentos correlatos ao que representará interagindo com o objeto, pois ela não nasce sabendo desenhar. Ela desenha o que as suas estruturas mentais possibilitam que perceba e não o que vê. Também, por meio de suas estruturas mentais, interpreta o que representou. Assim, a criança aprende a desenhar, construindo hipóteses e interpretações do mundo a sua volta (PILLAR, 1996). Por isso, a autora chama a atenção para a importância de não interferir no trabalho da criança ou sugerir algo durante a realização de sua atividade criadora, deixando-a livre para representar o que vem do seu pensamento.

Já Lev Vygotsky (1988) acredita que o desenho é o percussor da escrita, pois, com sua colaboração, as crianças começam a representar graficamente o mundo a sua volta. $\mathrm{O}$ ato de desenhar, prossegue Vygotsky, contém um grau de abstração ao puxar da memória lembranças para representá-las no papel. A fala também apresenta uma importante função, sendo ela a base da linguagem gráfica. De acordo com Vygotsky (1988), falar sobre o desenho infantil leva à reflexão sobre a linguagem, imaginação, percepção, memória, emoção e significação. Portanto é preciso compreender os processos psicológicos que estão envolvidos nesse ato. O desenho é 
um meio de comunicação muito importante para as crianças. É uma fonte de fácil entendimento entre elas (PEREIRA, 2016).

Por fim, de acordo com Derdyk (1989), a criança utiliza o desenho para diversos fins: como modo de expressão, como linguagem, como diversão. Trata-se de atividade que ela realiza sozinha, não precisando de companheiros, ditando suas próprias regras, aprendendo a estar só. O desenho, na perspectiva de Derdyk (1989), é o palco de suas criações, encenações e este universo de construção é particularmente dela. Ainda na visão do autor, quando a criança tem possibilidades de desenhar, tem condições de explorar maior número de grafismos, proporcionando, assim, uma compreensão mais aguçada. Tendo em vista a importância do desenho, o próximo tópico apresenta o caminho percorrido para a apreciação de estudos sobre a representação de animais pelas crianças.

\section{METODOLOGIA}

Pretende-se, neste trabalho, identificar os recursos metodológicos, os espaços de produção das pesquisas e como são analisadas as representações das crianças nos desenhos. Dado o grande número de teses, dissertações, artigos a esse respeito, adotaram-se alguns critérios para a seleção dos estudos a serem apresentados aqui como: pesquisas envolvendo sujeitos de 3 a 11 anos de idade; pesquisas cujo instrumento metodológico fosse o desenho; pesquisas na área de ciências; pesquisas com o objetivo de investigar a representação de animais pelas crianças. As palavras-chave para a busca dos trabalhos foram: desenho, concepção, percepção, crianças, ensino de ciências, linguagem, animais, educação ambiental, meio ambiente. Feita a leitura dos resumos desses trabalhos, quinze estudos versavam sobre o tema aqui investigado. Contudo, cinco trabalhos não se enquadravam nos critérios supracitados. Assim, elegeram-se dez pesquisas representativas para o campo investigado. As fontes de publicações examinadas nos últimos 12 anos foram: Google acadêmico, Scielo, Portal da Coordenação de Aperfeiçoamento de Pessoal de Nível Superior (CAPES); bibliotecas virtuais da Universidade Estadual de Campinas (UNICAMP); Revista de Ensino de Biologia (SBEnBIO); Revista Ciências em Extensão da Universidade Estadual Paulista Júlio de Mesquita Filho (UNESP); Revista Ensaio; Periódico Eletrônico do Fórum Ambiental da Alta Paulista; artigos do Congresso Nacional de Educação (CONEDU); portal da Universidade Federal Rural de Pernambuco (UFRPE) e Universidade Federal de Ouro Preto (UFOP); artigos 
do XIV Congresso Internacional de Tecnologia em Educação e Sapientia - Repositório da Universidade do Algarve. O quadro a seguir apresenta o conjunto dos artigos, dissertações e teses selecionadas:

Quadro 1: Produções acadêmicas sobre os desenhos de animais na infância

\begin{tabular}{|c|c|c|c|c|}
\hline Título do trabalho & Ano & Artigo & Dissertação & Tese \\
\hline $\begin{array}{l}\text { Desenhos, Palavras e Borboletas na Educação } \\
\text { Infantil: Brincadeiras com as Ideias no Processo de } \\
\text { Significação sobre os Seres Vivos }\end{array}$ & 2006 & & & $X$ \\
\hline $\begin{array}{l}\text { Representações da Mata Atlântica e de sua } \\
\text { Biodiversidade por meio dos Desenhos Infantis }\end{array}$ & 2007 & $\mathrm{X}$ & & \\
\hline $\begin{array}{l}\text { Desenhos: Representações de Aves no Ensino } \\
\text { Fundamental - Anos Finais, um Estudo Introdutório }\end{array}$ & 2011 & $\mathrm{X}$ & & \\
\hline $\begin{array}{l}\text { Concepções dos Alunos do } 1^{\circ} \text { Ciclo do Ensino Básico } \\
\text { sobre o Lobo Ibérico }\end{array}$ & 2012 & $X$ & & \\
\hline $\begin{array}{l}\text { Infância e Meio Ambiente: o Conhecimento das } \\
\text { Crianças de Serra Grande sobre os Peixes e Mar }\end{array}$ & 2013 & $X$ & & \\
\hline $\begin{array}{l}\text { O Ensino de Ciências nos Anos iniciais: A } \\
\text { Construção do Conhecimento Científico a partir de } \\
\text { uma Sequência Didática para o Estudo das Formigas. }\end{array}$ & 2013 & & $\mathrm{X}$ & \\
\hline $\begin{array}{l}\text { Crianças e suas Concepções sobre Morcegos no } \\
\text { Município de Maringá, Paraná. }\end{array}$ & 2016 & $\mathrm{X}$ & & \\
\hline $\begin{array}{l}\text { Percepções de crianças sobre aranhas em diferentes } \\
\text { escolas de Uruguaiana, com vistas à Educação } \\
\text { Ambiental }\end{array}$ & 2017 & $\mathrm{X}$ & & \\
\hline $\begin{array}{l}\text { Um Estudo sobre as Representações de Formigas por } \\
\text { Crianças do Fundamental I }\end{array}$ & 2017 & $\mathrm{X}$ & & \\
\hline $\begin{array}{l}\text { Insetos na Escola: Um estudo sobre a as } \\
\text { Representações de Formigas nos Anos Iniciais do } \\
\text { Ensino Fundamental }\end{array}$ & 2019 & & $X$ & \\
\hline
\end{tabular}

Fonte: As autoras

\section{ANÁLISES E RESULTADOS}

As análises e resultados das produções examinadas neste estudo serão apresentadas seguindo a ordenação dos temas dispostos no quadro acima. Assim sendo, Dominguez (2006), em sua pesquisa, buscou entender quais os conhecimentos as crianças possuíam e quais adquiriram sobre o inseto em estudo: as borboletas. Ela realizou seu estudo em uma creche,

\footnotetext{
${ }^{6}$ Este artigo foi considerado por apresentar em sua amostra alunos do $5^{\mathbf{o}}$ ano -10 e 11 anos de idade.
} 
localizada dentro do campus da Universidade de São Paulo. Por 6 meses, a pesquisadora acompanhou uma turma de crianças de 4 anos. Considerando importante conhecer o contexto em que seriam produzidos os desenhos, Dominguez (2006) optou por utilizar uma metodologia qualitativa de pesquisa, permitindo interferências por parte do pesquisador. Ela participou ativamente das rodas de conversas, caracterizando a pesquisa em questão em observação participante.

Analisando a linguagem gráfica e verbal, Dominguez (2006) buscou perceber a organização espacial e as concepções pedagógicas presentes na turma. O caderno de campo serviu como estratégia para a realização dos registros, principalmente quando não havia desenhos nem entrevistas programadas no encontro. Além disso, todas as aulas foram gravadas em áudio e vídeo. Para a realização dos desenhos, inicialmente as crianças foram convidadas a produzir, em papel A4 e a lápis, desenhos relacionados à vida das borboletas. Desse processo participaram 7 crianças que foram divididas em dois grupos. Também foram realizados passeios pelo bosque do campus e observações no parquinho da creche. Os critérios para a análise dos desenhos não ficaram claros na pesquisa. $\mathrm{O}$ interesse das crianças pelo tema e o número de registros arquivados sobre os desenhos foram critérios relevantes para escolha do material analisado.

Concluiu a autora que as concepções das crianças sobre o modo de vida e características das borboletas basearam-se nas imagens apresentadas nas aulas. Os insetos adultos foram representados com asas. Como não havia um padrão determinando a quantidade desenhada, elas também acrescentaram antenas, cabeças e pernas. As borboletas apareciam sempre interagindo com plantas ou outros animais. Vegetais apareciam ora como alimentos, ora como esconderijo, ora como habitat. Segundo a autora, nos primeiros desenhos, as crianças representaram as borboletas com poucas características morfológicas. Mas, com o desenvolvimento das falas e observações, ampliaram-se suas concepções, inclusive abandonando aspectos humanos englobados anteriormente nas borboletas. E então, acrescentaram o que era mais real nas borboletas mostrando a evolução das observações. Assim, concluiu-se que o conceito de representação desenvolvido por Dominguez (2006) parece problemático, porque estabelece uma relação causal entre o objeto externo e a consciência, como uma relação de correspondência ou semelhança, conforme indicado por Japiassu e Marcondes (2001). 
Por sua vez, Schwarz e colaboradores (2007) investigaram as representações da Mata Atlântica e sua biodiversidade nos desenhos infantis. Esse trabalho analisou 395 desenhos de crianças com idade entre 6 e 14 anos, habitantes de área urbana de Joinville. Teve por objetivo verificar os conhecimentos desse grupo social sobre o bioma em questão. Para isso, os autores investigaram quais os ecossistemas eram mais representados nos desenhos e se enfatizavam a diversidade da flora e da fauna. Concluíram os autores que, de modo geral, a criança gosta muito de desenhar, mas o desenho ainda é um método pouco explorado para construir noções dos conceitos científicos (DOVE, EVERETT e PREECE, 1999 apud Schwarz et. al, 2007). Vale lembrar que os trabalhos de Luquet, Piaget e Gobbi são citados pelos autores como referências para a interpretação do desenho infantil. Contudo, na análise dos desenhos não fica claro como esses autores auxiliaram-nos na interpretação das imagens. Ressalta-se, também, que o levantamento das percepções das crianças e adolescentes, perante a biodiversidade da Mata Atlântica, foi efetuado junto aos alunos de um colégio particular, da cidade de Joinville. Fizeram parte da população-alvo, 395 alunos de seis a 14 anos de idade, que frequentavam da $1^{\mathrm{a}}$ a $8^{\mathrm{a}}$ séries do Ensino Fundamental, sendo 216 do gênero feminino e 179 do masculino, totalizando $62 \%$ da população total da escola. Quanto à coleta de dados, foram adotados os seguintes procedimentos metodológicos: solicitar aos estudantes um desenho sobre a Mata Atlântica; realizarem a tarefa sem se preocupar com a habilidade em desenhar, mas sim representar o que vem à mente referente ao tema; redigir um texto sobre a produção realizada. Os participantes foram divididos em dois grupos: crianças menores, da $1^{\mathrm{a}}$ a $4^{\mathrm{a}}$ séries $(140$ estudantes), e crianças maiores, da $5^{\mathrm{a}}$ a $8^{\mathrm{a}}$ séries (255 alunos).

O tempo dado para confecção dos desenhos foi de sessenta minutos. Não houve discussão antecedente à sessão de desenho. Quanto à análise dos desenhos, segundo Schwarz e colaboradores (2007), eles foram quantificados e classificados observando-se as semelhanças, modelos e estruturas. Com base nestes dados, os desenhos foram divididos nos seguintes temas: i) tendência dos elementos desenhados; ·ii) o conjunto total desses elementos que determina o ecossistema desenhado; e iii) a classificação dos desenhos. Os animais mais representados foram as aves, presentes em 52,2\% dos desenhos. Mas, somente 11,9\% destes apresentavam aves com forma específica, e não o simples rabisco de aves no céu. A onça foi o segundo animal mais representado $(14,4 \%)$, seguida de cobras $(13,7 \%)$, borboletas $(13,7 \%)$, peixes $(8,9 \%)$, macacos $(8,6 \%)$ e demais animais $(15,1 \%)$. A presença humana ocorreu em 7,6\% dos desenhos. De acordo com os autores, houve diferenças quanto ao gênero e faixa etária na representação 
dos animais. As meninas desenharam com maior significação as borboletas e os meninos deram maior importância às aves. Já as crianças menores preferiram desenhar borboletas, onças, cobras, peixes, macacos, leões e insetos. Já as maiores, deram maior significação às aves. Por fim, em alguns desenhos, viam-se aves e macacos nos ramos de grandes ou pequenas árvores, serpentes escondidas ou enroladas nos galhos e o mar, rios e cachoeiras repletos de peixes. A onça foi representada livre no seu habitat natural.

Concluíram os autores dessa pesquisa, que as crianças realçaram na Mata Atlântica, a flora. Com relação à fauna, predominaram os animais exóticos da fauna brasileira. O leão foi o animal exótico mais desenhado, mais frequente entre crianças menores do que entre as maiores. Animais como urso, girafa, tigre, elefante foram representados em $2 \%$ dos desenhos elaborados pelas crianças menores e 0,5\% pelas maiores. Para Schwarz e colaboradores (2007), o destaque à fauna exótica pode estar relacionado com a importância dada a ela em livros, revistas e programas audiovisuais para crianças. E, no caso das crianças maiores, possuem outras fontes de informações, além da observação direta de diferentes tipos de animais.

Por sua vez, a pesquisa de Silva e Bartosezeck (2011) dedicou à compreensão do que pensam as crianças quando falam de aves. Silva e Bartosezeck (2011) fizeram uso do desenho seguido de entrevista. Com o aporte de Luquet (1927), desenvolveram esse trabalho, com ênfase nos conhecimentos sobre aves e o desenho infantil. Assim, em uma escola estadual de Pernambuco, os pesquisadores convidaram 77 crianças com idades entre 10 a 13 anos, para desenharem aves em folhas A4 e lápis preto e, após o desenho, participarem de uma entrevista semiestruturada que consistia em responder cinco perguntas a saber:

1. Quantas/quais aves você conhece?

2. Nomeia-as.

3. Onde você viu essa ave?

4. Das aves que você conhece, onde as viu?

Posteriormente, os entrevistadores apresentaram fotografias de várias aves e pediram a elas que dissessem o nome da ave e onde elas a viram. Todas as crianças realizaram o desenho, mas nem todas responderam às perguntas apresentadas.

Como os sujeitos da pesquisa apresentavam idades variadas, os pesquisadores tiveram condições de realizar uma análise comparativa. Pelos desenhos, notaram que as crianças maiores representaram sua ave com maior identificação às características morfológicas. As crianças mais novas desenharam pássaros com sobrancelhas, cílios e boca. O ambiente 
doméstico foi o local em que a maior parte das crianças representaram suas aves: galinhas, pombas, patos e gansos. Poucas crianças desenharam aves com detalhes, como: bicos, garras e penas. Elementos culturais também foram observados, como representações de pássaros na gaiola. Mas, todos os desenhos representaram aves com olhos arredondados. Em alguns desenhos, as aves tinham cobertura em traços ora lineares, curvos, ora ondulados. Algumas crianças representaram as aves pousando em superfícies, sedimentos ou base que serviam de suporte aos organismos vivos e além de outros que os pesquisadores não identificaram. E, em 24 desenhos, as aves apareceram pousadas em diferentes substratos, como: água, pedaço de pau, árvores, pedras e ninhos. Outras crianças representaram suas aves voando ou com asas abertas. Embora Silva e colaboradores (2011) relacionaram Luquet no seu aporte teórico, a interpretação dos desenhos não demonstra diferenciação entre os significantes e significados construídos pelas crianças.

Já Glória et al (2012) analisaram as concepções de crianças de 6 a 8 anos de idade sobre o lobo ibérico. Para tal, as autoras solicitaram às crianças de 164 escolas portuguesas que desenhassem um lobo. Segundo os autores, essas crianças não apresentaram nenhum tipo de informação formal dos hábitos e anatomia desse animal. O objetivo da pesquisa era compreender como as crianças representavam esse animal e sua interação com o ser humano. Para isso, os autores elaboraram um quadro com as categorias que foram usadas para codificar os desenhos apresentados pelos alunos.

Para análise desse material, os pesquisadores, em concordância com Bogdan e Biklen (1994), analisaram coletivamente os desenhos a fim de diminuir as distorções provenientes da observação de apenas um investigador. Não há, na pesquisa de Glória e colaboradores (2012), referências de autores que investigam os desenhos das crianças. O conceito de representação é abordado com um sentido mais restrito, como lembranças simbólicas da realidade. O quadro de categorias foi composto tendo em vista as características do animal, como: reprodução, caça ao lobo ibérico, cativeiro, alcateia, predação, temperamento, antropormifização, sons, enquadramento ecológico. Cada criança participante da pesquisa realizou apenas um desenho, mas esse desenho poderia ser enquadrado em diversas categorias do quadro, diante das características apresentadas. Inicialmente, os pesquisadores utilizaram um procedimento quantitativo, contabilizando as obras em relação aos aspectos comuns observados. A maior parte das crianças $(75 \%)$ representou o lobo no contexto ecológico, atestando que elas possuem noções básicas sobre o ecossistema em que o animal vive. Em 34\% dos desenhos, o lobo foi 
associado a situações noturnas, uivando para a lua. Já 33\% das crianças desenharam o lobo com características antropomórficas. Quanto às representações do lobo predador, apenas $12 \%$ das crianças desenharam-no nessa perspectiva. Em 11\% dos desenhos, as crianças representaram alcateias e em $13 \%$ dos desenhos não foi possível encaixar as representações em nenhuma categoria, sendo enquadradas como outras representações do lobo.

Diante desses resultados, as autoras concluíram que, apesar dos preconceitos existentes na sociedade contra os lobos, foi possível perceber que as crianças pesquisadas não generalizam o medo à espécie, mencionando sempre os lobos como relevantes para a natureza. Concluíram também que as crianças conheciam características do lobo, porém, algumas ainda mantinham a visão estereotipada e deturpada dos lobos, associando-os ou a seres agressivos ou a animais que devem ser caçados.

Com referência aos estudos de Santana e Fiamengue (2013), os autores investigaram o conhecimento e a percepção das crianças da $4^{\mathrm{a}}$ série de uma escola municipal, em um vilarejo baiano, que possuíam algum vínculo com pescadores, peixes e o mar. Ali buscaram entender a interação das crianças com os animais marinhos e a construção desse conhecimento entre as gerações. Para tal, os autores deslocaram-se até a escola do vilarejo onde realizavam produções de texto e desenhos junto às crianças e, assim, entenderem quais seriam os conhecimentos que elas possuíam sobre os peixes.

Quanto às análises dos desenhos, tiveram, como base, os textos elaborados pelas crianças. De posse dos desenhos das crianças, as pesquisadoras perceberam que elas sabiam muito sobre os peixes. Foram apresentadas obras nas quais foi possível perceber que as crianças conheciam peixes de diferentes tamanhos e cores, com nadadeiras caudais diferentes, isso levou as pesquisadoras a acreditarem que as crianças eram capazes de identificar inúmeras espécies e em distintas fases do desenvolvimento, mencionando, inclusive, aspectos morfológicos de cada uma delas. Também, algumas, apresentaram a cadeia alimentar dos peixes, outros retrataram a interação do peixe com o ser humano, mostrando crianças nadando junto com os peixes, outro, ainda, desenhou seu peixe no aquário, em ambiente domiciliar. Afinal, as pesquisadoras concluíram que os desenhos e os textos das crianças transmitiam conhecimentos e sentimentos. Esses conhecimentos eram construídos pela interação delas com os animais e decorrentes de conhecimentos produzidos entre as gerações. Ressalta-se, ainda que, Santana e Fiamengue (2013), trabalharam com duas formas de representação para compreender o desenho das 
crianças. Resta dizer que, também nesta pesquisa, o conceito de representação é imagem ou ideia que as crianças têm dos peixes.

$\mathrm{Na}$ sequência, dado o objetivo do presente estudo, apresenta-se a dissertação de Dalladona (2013). A autora em sua investigação, procurou compreender o que as crianças sabiam sobre as formigas. $O$ estudo foi realizado com crianças do $2^{\circ}$ ano do Ensino Fundamental, em uma escola pública localizada em Timbó, Santa Catarina. Os sujeitos pesquisados eram 20 crianças com idades entre 7 e 8 anos. Para a coleta de dados, Dalladona utilizou as observações realizadas durante as aulas, devidamente registradas no diário de bordo. Foram utilizadas fotos e gravações em vídeos. Também, as produções dos alunos realizadas em sala de aula, coletivamente ou individual, constituíram fontes de informações importantes para a elaboração do resultado da pesquisa. Identificados os conhecimentos prévios das crianças, a pesquisadora propôs algumas questões em sala de aula. Ao serem convidadas para produzir um desenho, as crianças discutiram vários aspectos da vida das formigas. O açúcar foi o alimento mais comentado pelas crianças. No decorrer da tarefa, surgiram dúvidas relativas aos números de pernas das formigas e sobre as antenas. Os desenhos apresentados foram acompanhados por textos. Assim, com aulas expositivas, experiências, passeios, palestras, elaboração de registros, relatórios, modelos, leituras, pesquisas, entrevistas, reflexões, desenhos, entre outras atividades, Dalladona conseguiu proporcionar as crianças um conjunto de saberes mais próximos dos conhecimentos científicos sobre as formigas. O conceito de representação não é apresentado como parcial em relação ao que representa. Ele é indicado como semelhante na maneira de ver e compreender o conteúdo conceitual.

Por sua vez, Filho et al (2016) realizaram um estudo para avaliar a concepção das crianças de 3 a 12 anos de idade sobre os morcegos. Os pesquisadores montaram uma tenda em praça pública onde eram expostos objetos e painéis informativos relacionados aos morcegos, ressaltando a importância ecológica deles, inclusive promovendo condições de tocar em um animal vivo. Também montaram uma caverna de tecido, onde o visitante poderia vivenciar o habitat natural desses mamíferos. Quanto aos participantes dessa experiência, foram convidadas mais de 40 crianças.

Para a coleta de dados, as crianças foram convidadas a desenhar o que sabiam sobre os morcegos e responder, em entrevistas semiestruturadas elaboradas pelas autoras, às seguintes perguntas:

1. Qual a sua idade? 
2. O que são os morcegos?

3. Já viu algum?

4. O que eles comem?

5. Você tem medo deles? Se sim, por que?

Tanto o desenho, quanto as respostas da entrevista foram espontâneas. Enquanto as crianças desenhavam, os monitores realizavam a entrevista. Nem todas as crianças se interessaram em responder às perguntas, bem diferente do interesse apresentado para a realização dos desenhos.

Para a análise dos desenhos, foram determinadas cinco categorias, sendo elas: antropomorfização, caracterização estereotipada, outros animais, inserção no ambiente. Totalizaram-se 42 desenhos, dos quais, 13 apresentaram o morcego com características antropomórficas. A representação estereotipada dos morcegos, por exemplo, sangue, olhos vermelhos e caninos exagerados apareceu em 15 desenhos. Em 13 desenhos, as crianças representaram seus morcegos com características de outros animais, com asas semelhantes às dos insetos e patas de aves, enfim, grupo de animais próximo do cotidiano delas. Ao analisar a inserção dos morcegos no ambiente, os pesquisadores constataram maiores acertos: 18 crianças demonstraram possuir conhecimentos sobre a ecologia dos morcegos. Seus desenhos mostraram morcegos voando em meio às árvores, despertos à noite, próximos a cavernas e em grupos. Em 2 desenhos, foram visíveis a mudança de concepção da criança e a aquisição de novos conhecimentos. Isso foi percebido nos detalhes como o formato dos olhos e asas, detalhes no corpo.

Finalmente, os pesquisadores concluíram que os morcegos ainda são cercados por mitos, o que mantém o ser humano longe deles. Contudo, as crianças pesquisadas daquela região não os veem como animais perigosos ou ruins. Acredita-se que essa mudança se deu por trabalhos de divulgação científica e educação ambiental, garantindo acesso a informações corretas e a melhora no processo de ensino. Na pesquisa de Filho et al (2016), o conceito de representação é utilizado como lembranças simbólicas para analisar aspectos morfológicos dos morcegos.

Sobre a educação ambiental, no interior de duas escolas, uma localizada em área urbana e outra em área rural, Jotta et al (2017) buscaram verificar quais as percepções das crianças de 7 a 11 anos do Ensino Fundamental sobre aranhas. O objetivo dos autores era promover a sensibilização das crianças para a Educação Ambiental. Eles Utilizaram, para esse fim, o 
desenho das crianças, seguido de um questionário por eles construído sobre os seres vivos, evidenciando as aranhas. Após essa etapa, as crianças foram chamadas para a entrevistada, individualmente, fora da sala de aula. A entrevista consistiu na apresentação às crianças de cartões com imagens em preto e branco, de animais invertebrados cujo o objetivo era dizer o nome dos animais. Os animais desenhados nos cartões eram: borboleta, aranha, tatu de jardim, besouro, gafanhoto, minhoca. Ao término da entrevista, as crianças voltaram à sala de aula onde houve uma explicação da biologia dos seis animais, com ênfase na aranha. Os pesquisadores esperaram em torno de 20 dias para retornar à escola e realizar o segundo momento da pesquisa: convite às s crianças para desenharem uma aranha. Essa pausa foi proposital para que os pesquisadores tivessem condições de obter dados para a realização de um estudo comparativo entre os desenhos realizados pelas crianças.

Para a análise dos dados, organizaram-se três etapas: representação gráfica dos animais; análise das entrevistas; representação gráfica das aranhas. Como foco do estudo era o conhecimento das características morfológicas das aranhas, os pesquisadores analisaram esses aracnídeos baseando-se nas seguintes categorias: quantidade de pernas (8); corpo dividido (afalotórax e abdômen); presença de quelíceras (estruturas utilizadas para a manipulação de alimentos e inoculação do veneno); presença de teia. Segundo os pesquisadores, as crianças da escola urbana, após as explicações, desenharam a aranha com o número correto de pernas. Já a presença de teia apareceu em maior número nas obras das crianças da escola rural, levando os pesquisadores a concluírem a valorização dessa característica.

Concluíram Jotta et al (2017) que houve aumento expressivo nos desenhos das crianças, quanto aos aspectos morfológicos, após o estudo formal, demonstrando a capacidade da maior parte das crianças em reconhecer detalhes nos animais. Os autores concluíram que o medo predominava quando o assunto era aranha, possivelmente por vivências individuais de cada criança. Jota e colaboradores (2017) também recorreram ao conceito de representação como lembranças simbólicas para analisar aspectos morfológicos das aranhas.

Já Rodrigues e Almeida (2017) investigaram as representações de formigas por crianças de 9 e 10 anos, que não tiveram nenhum estudo sistemático sobre esse inseto em ambiente escolar. As pesquisadoras optaram por realizar uma pesquisa exploratória qualitativa. A pesquisa ocorreu em uma escola pública sendo todos os encontros devidamente gravados. A sala de aula era constituída por 26 crianças de 9 e 10 anos. Na sala de aula foram distribuídas folhas A4 às crianças solicitando que realizassem um desenho de uma formiga apenas com as 
lembranças desse inseto. Não foi realizada nenhuma intervenção antes da aula, deixando-as livres para desenhar apenas as características do inseto que recordavam. Em seguida, foi realizada a escuta das falas das crianças que explicitavam o que haviam desenhado. Após a entrevista, os desenhos foram analisados minuciosamente. As pesquisadoras realizaram anotações no caderno de campo, pertinentes às singularidades de cada desenho. A partir das anotações e das características recorrentes em cada obra sobre as formigas, elas elegeram categorias que serviram de referência para as análises dos desenhos. São elas: ciclo de vida, alimentação, habitat, morfologia. Em 15 produções foram observados desenhos de formigas com características de lagartas ou outros animais. Outras 22 crianças desenharam a formiga com antenas. O número de pernas desenhadas variou entre 3 e 9 . Do total dos desenhos, 16 crianças representaram a formiga com o corpo segmentado em três partes. E, em apenas 3 desenhos, encontraram-se estruturas que lembram mandíbulas. Olhos compostos também não foram representados.

Quanto à alimentação das formigas, o estudo indica que apareceram nos desenhos folhas e frutas. As crianças não representaram formigas se alimentando de outros insetos. Em nenhum desenho foi encontrada a presença de ovos ou algo que se referisse à metamorfose da formiga. Quanto à vida social, quatro crianças desenharam-nas em fila e em dezessete representações foi possível notá-las em grupos. E, um desenho, apresentou a formiga com uma coroa, o que levou as pesquisadoras a inferirem que, possivelmente, para as crianças existe um poder explícito e consciente da rainha na colônia. Em 13 desenhos, foi possível perceber que as crianças representaram suas formigas com características antropomórficas. As pesquisadoras concluíram que as crianças têm ideias quanto à variabilidade entre as espécies. Diante dos dados expostos, concluíram Rodrigues e Almeida (2017) que, para as crianças aprenderem sobre formigas, é necessário mais que falar ou mostrá-las em livros, é necessário que as aulas de Ciências formalizem o estudo dos insetos que estão ao alcance dos olhos delas. No estudo em questão, não há referências a autores que investigam os desenhos das crianças. $\mathrm{O}$ conceito de representação se apoia nas lembranças simbólicas da realidade para a identificação de características morfológicas dos desenhos das crianças.

A dissertação de Rodrigues (2019) investigou a representação de formigas por crianças de 9 a 10 anos. Para realizar essa pesquisa, Rodrigues utilizou o estudo de caso. Desse modo, ela construiu uma sequência didática para compreender o olhar da criança sobre as formigas. Quanto aos referenciais teóricos para análise dos desenhos Rodrigues baseou-se em: Piaget 
(1978), Pillar (1996) e em Padilha (1990) para trabalhar com o conceito de representação nos desenhos infantis. A pesquisa foi realizada em uma escola pública e teve a duração de 6 meses. A sala de aula onde a investigação foi realizada era composta por crianças de perfis diversificados e níveis socioeconômico-cultural diferentes. Foram analisados 30 desenhos de 10 crianças que participaram de todas as aulas. Os desenhados analisados foram recolhidos em momentos distintos da sequência didática. O primeiro deles tinha, como objetivo, compreender as concepções prévias das crianças. Para essa análise foi utilizado um quadro de categorias construídos pela pesquisadora que contemplava aspectos relativos à morfologia e aspectos dos traços dos desenhos.

Assim, durante quatro encontros, as 20 crianças participantes da pesquisa, que elas desenharam formigas. Os desenhos duraram cercam de 30 a 40 minutos. Segundo a autora, todos os alunos se mostraram satisfeitos com o trabalho. Após cada desenho, todas as crianças eram convidadas a comentar seu trabalho.

$\mathrm{Na}$ maioria dos desenhos que antecederam à sequência didática, as formigas não apresentaram muitos traços morfológicos, desenharam apenas pequenos animais que foram identificados como insetos. A maioria das formigas foram representadas na cor preta, caminhando para o formigueiro, fato que indica o entendimento de que alguns desses insetos são muito pequenos. Muitas crianças destacaram a formiga-rainha, que foi desenhada longe do grupo e em tamanho maior, com traços antropomórficos ressaltados, como o sorriso da formiga, bípede e a sua coroa. $\mathrm{O}$ antropomorfismo foi uma característica dos primeiros desenhos. $\mathrm{Na}$ maioria dos desenhos, a autora indica a falta de proporcionalidade, rebatimento e transparência.

Nos desenhos apresentados após a sequência didática, a maioria das crianças desenhou o corpo das formigas dividido em três partes. Em alguns, o abdômen aparece mais volumoso. Elas indicaram em suas falas os nomes dos segmentos desse inseto. De maneira geral, as formigas foram representadas com três pernas, antenas e mandíbulas para carregarem os alimentos, apesar de algumas folhas serem carregadas pelas costas. A maioria dos desenhos eram bidimensionais e não apresentavam desvios de esquemas. Aspectos do rebatimento também foram percebidos. Nos últimos desenhos, não havia transparência e a proporção das figuras estava adequada a que se propôs representar. Verificou-se, também, que a interação das crianças como o material didático apresentado culminou nas representações de formigas com detalhes próximos do real e apropriaram-se dos conceitos apresentados, comprovados na entrevista. Observa-se, nos pressupostos teóricos do trabalho de Rodrigues (2019), que a 
interpretação dos desenhos das crianças baseou-se em autores que analisam o desenho. Contudo, o uso do conceito de representação também na investigação supracitada parece problemática porque é entendida uma relação causal entre o objeto externo e a consciência. Diante do exposto parece que as análises morfológicas das formigas tiveram por pressuposto de que a consciência é capaz de apreender diretamente o objeto externo. Isso revela uma concepção positivista da ciência que visa à investigação das causas primeiras e finais da natureza, um conhecimento absoluto, apresentando os fenômenos como produtos de ação direta e contínua de agentes sobrenaturais (SOUZA, 2020).

\section{CONSIDERAÇÕES}

O desenho infantil, objeto deste trabalho, é um instrumento valioso para compreender o desenvolvimento das crianças e suas concepções sobre o mundo natural. Afinal, ainda bem pequenas, as crianças estabelecem relações com o mundo que as rodeiam, e vão aprendendo a conhecê-lo. Posto isso, com o objetivo de apresentar um panorama da literatura sobre o desenho infantil das investigações citadas neste trabalho, apenas duas não são artigos, o que pode significar que esse tema é pouco estudado. O número de trabalhos acadêmicos produzidos no intervalo de 2006 a 2019 também não é expressivo.

Com relação aos temas estudados, as pesquisas supracitadas trabalham com o conceito de representação visto como uma imagem que traduz uma concepção do animal, tendo como sentido, tornar presente essa imagem implícita no desenho. Assim, o conceito de representação é entendido como uma relação de semelhança entre os aspectos morfológicos dos animais e a imagem que as crianças apresentam deles nos desenhos, sem a problematização da evolução das ideias das crianças, ou seja, a problematização da compreensão que as crianças apresentam do animal pelas diferentes linguagens e também das questões culturais envolvidas nesse processo.

Conforme já dito neste estudo, para Laburú e colaboradores (2013), toda representação é cognitivamente parcial em relação ao que representa e não é semelhante na maneira de ver e compreender um mesmo conteúdo conceitual. Desse modo, entendemos que as crianças representam parcialmente os animais, tanto pelo limite da representação como do limite do conhecimento que apresentam dos mesmos. Mas, as investigações que estudam as representações das crianças se limitam ao conteúdo das características físicas dos animais - a 
abstração empírica. E, segundo os estudos de Piaget (1972). A abstração empírica deve colaborar para as operações mentais operações mentais do "objeto" presente na mente.

Assim, as pesquisas aqui mencionadas buscam apenas a ausência daquilo que pode ser visto nos animais, mas não buscam compreender as razões pelas quais as crianças, de cada faixa etária ou cultura, representam os animais de determinado modo. Dessa forma, pode-se afirmar que o sentido atribuído ao termo representação nas pesquisas fica restrito às lembranças simbólicas da realidade, conforme já indicado pelos estudos de Piaget, (1978, apud PILLAR, 1996). Em relação à diversidade de animais representados temos: aracnídeos, peixes, mamíferos e insetos. Nesse sentido, pode-se concluir que houve uma diversificação dos animais desenhados pelas crianças.

Certo é que a maioria dos pesquisadores tinha como objetivo geral identificar o conhecimento prévio das crianças sobre alguns animais. Cinco pesquisadores tiveram seu foco no ensino fundamental, nos anos inicias, com crianças de 6 a 11 anos. Apenas uma pesquisadora trabalhou com crianças da educação infantil. E apenas uma pesquisa contemplou ambas as escolaridades, com um público de crianças de 3 a 11 anos. Quanto aos animais presentes nos desenhos, a maior parte deles, relacionavam-se com o cotidiano das crianças. A maioria dos desenhos apresentou uma visão estereotipada sobre os animais, marcada pelo temor. Mas, aqueles que faziam parte do cotidiano das crianças se destacaram pela riqueza de detalhes e conhecimento que possuíam.

Com efeito, a maior parte ocorreu no ambiente escolar. A facilidade dos pesquisadores de encontrar, no interior da escola, o público desejado para atingir seus objetivos, possivelmente foi a justificativa para tantas pesquisas realizadas nesse ambiente. Apenas uma pesquisa foi realizada fora do ambiente escolar o que proporcionou aos pesquisadores obter um conjunto de crianças com idades variadas, conseguindo, assim, identificar diferentes percepções sobre o assunto estudado, em um mesmo grupo.

Quanto à metodologia das pesquisas, estudiosos como Ludke e André (1986), Bogdan e Biklen (1994) e Flick (2004) deram suporte para a sua realização. Contudo Gil (2008) foi o que mais se destacou pelos pesquisadores. Observou-se, na maioria das investigações, que o desenho não serviu como instrumento de intervenção, comparação ou debate entre as crianças. E, apenas uma pesquisa não utilizou as falas das crianças como método para análise, ficando apenas com o desenho, também realizado em grupo. Também, apenas uma pesquisa citou as questões culturais envolvidas no ensino e aprendizagem sobre a representação dos animais. 
Todos os pesquisadores corroboraram com a ideia de que o desenho infantil é importante para observar a evolução e concepções das crianças. Entretanto, para muitos o desenho só é importante no momento inicial do trabalho quando as crianças são convidadas a desenhar.

Em suma, o conceito de representação não foi definido pela maioria dos pesquisadores, embora utilizem esse termo. Vale lembrar que, com exceção de Dominguez (2006), os demais pesquisadores são biólogos, o que pode estar relacionado com a preocupação em enfatizar a morfologia dos animais nos desenhos. Estudos de Piaget, Vygotsky e Wallon foram pouco explorados em seus estudos. Nessa perspectiva, pesquisadores não usam como referência os estudos da psicologia para interpretação dos desenhos infantis.

Contudo, a contribuição desses autores é original e importante para os estudos futuros porque indicam caminhos e afirmam o compromisso de olhar os desenhos das crianças sobre os animais como um instrumento de investigação.

\section{REFERÊNCIAS}

ALMEIDA, S.A; LIMA, G.S; PEREIRA, B. L.A; Des/fiando diálogos sobre o conceito de cadeia alimentar em uma aula de Ciências nos anos iniciais do Ensino Fundamental. Revista Ensaio: Pesquisa em Educação em Ciências, v.21, Belo Horizonte, 2019.

BOGDAN, R; BIKLEN, S. Investigação Qualitativa em Educação. Porto: Porto Editora; 1994.

COSTA-NETO; M. CARVALHO, Percepção dos insetos pelos graduandos da Universidade Estadual de Feira de Santana, Bahia, Brasil. Acta Scientiarum, 2000.

DALlADONA, K.G. O Ensino de Ciências nos Anos iniciais: A Construção do Conhecimento Científico a partir de uma Sequência Didática para o Estudo das Formigas. Dissertação. Programa de Pós Graduação em Ciências Naturais e Matemática do Centro de Ciências Exatas e Naturais da Universidade Regional de Blumenau, 2013.

DERDYK, E. Formas de pensar o desenho. São Paulo: Scipione, 1989.

DOMINGUEZ, C. R.C. Desenhos, Palavras e Borboletas na Educação Infantil: Brincadeiras com as ideias no Processo de Significação sobre os Seres Vivos. Tese. São Paulo. 2006.

FILHO, H. O., RIBEIRO, N. C.G., SILVA, R.G. Crianças e suas concepções sobre morcegos no município de Maringá, Paraná. $7^{\circ}$ Congresso brasileiro de extensão universitária da Universidade Federal de Ouro Preto - UFOP/MG. 07 a 09 de setembro de 2016. 
GARCÍA, C., PAREDES, R. (2015). Reducing the educational gap: good results in vulnerable groups. Journal of Development Studies, 2015.

GLÓRIA, A. C., ROSA, C., CAVADAS, B. Concepções dos alunos do $1^{\circ}$ ciclo do ensino básico sobre o lobo ibérico. Revista Electrónica de Enseñanza de las Ciencias Vol. 11, No 3, 2012.

HALL, S. A identidade Cultural na pós-modernidade. 10 ed. Rio de Janeiro: DP\&A, 2005.

JACKSON, M. D., SPENCER, S. Anais da Sociedade Entomológica da América , Volume 110, Edição 5, setembro de 2017, páginas 439-448, https://doi.org/10.1093/aesa/sax055

JOTTA, P. D. A. C. V., COSTA, M. T., QUEROL, M. V. M., PESSANO, E. F. C.

Percepções de crianças sobre aranhas em diferentes escolas de Uruguaiana, com vistas a educação ambiental. Revista Educação Ambiental em Ação, No. 61, setembro/novembro de 2017.

LABURÚ, C. E.; ZOMPERO, A. F.; BARROS, M. Vygotsky e múltiplas representações: leituras convergentes para o ensino de ciências. Caderno Brasileiro de Ensino de Física, v. 30, p. 7-24, 2013.

LOPES,P. P. Franco, I. L. O., Santana-Reis, V. G., LOPES, P. P. Insetos na Escola: Desvendando o Mundo dos Insetos para as Crianças. Revista Ciências. Ext. v.9, n.3, p.125$134,2013$.

LOWENFELD, V. Desenvolvimento da capacidade criadora. São Paulo: Mestra Jou, 1977.

LÜDKE, M.; ANDRÉ, M. E. D. A. Pesquisa em educação: abordagens qualitativas. São Paulo: EPU, 1986.

LUQUET, G.-H.(1927-1969) O desenho infantil. Porto: Ed. Minho, Trad: Maria Teresa Gonçalves de Azevedo. 1969.

MARTI, E. La perspectiva piagetiana de los años 70 y 80: de las estructuras al funcionamiento. Anuario de psicología, Barcelona, v. 44, 1990.

MÈREDIEU, Florence. O desenho infantil. São Paulo: Cultrix, 1979. Trad: Álvaro Lorencini e Sandra M. Nitrini, 1974.

MEDIOLI, F. O fascinante mundo das formigas. Jornal o tempo. 2017.

PEREIRA, A. C. A importância do desenho infantil para o desenvolvimento das crianças em jardim de infância. Universidade do Algarve. 2016.

PEREIRA, L.T. K. 2005. O desenho infantil e a construção da significação: um estudo de caso. Portal da Unesco. Disponível em: http://portal.unesco. org/culture/; acessado em: 27/02/2018. 
PIAGET, J. A representação do mundo na criança. Rio de Janeiro. Record. 1926

PIAGET, J. A formação do símbolo na criança. Rio de Janeiro: Guanabara Koogan, 1978.

PILLAR, A. D. O desenho como sistema de representação. Porto Alegre: Arte médicas. 1996.

RODRIGUES, G. B. A. ALMEIDA, S. A. A. Um Estudo sobre as representações de Formigas por Crianças do Fundamental I. Ensenãnza de las Ciencias, N. ${ }^{\circ}$ Extraordinário 2017.

RODRIGUES, G.B.A. Insetos na escola: Um estudo sobre a representação de formigas nos anos iniciais do Ensino Fundamental. Dissertação. Programa de Pós-Graduação em Educação da Universidade Federal de Ouro Preto, 2019.

ROCHA, A. C. PINTO E.D.J ARAÚJO, M. F. F. D. Desmistificando a Classe Insecta no Ensino Fundamental: Oficina Aplicada em Turma de Sétimo Ano. Revista SBEnBIO. Número 7. Outubro de 2014.

SANTANA, L. C. FIAMENGUE, E. C. Infância e meio ambiente: o conhecimento das crianças de serra grande sobre os peixes e mar. Cadernos Ceru v. 24, n. 1, 08 Laine Santana. 2013.

SOUZA, D. C. O Positivismo de Auguste Comte e a educação científica no cenário brasileiro. Revista da Rede Amazônica de Educação em Ciências e Matemática. Cuiabá, MT, V. 8, No 1, 2020.

SCHWARZ, M. L.; SEVEGNANI, L.; ANDRÉ, P. Representações da Mata Atlântica e sua biodiversidade por meio dos desenhos infantis. Ciência \& Educação, v. 13, n. 3, p. 369 388, 2007.

SILVA, I. D. G. M.D. BARTOSEZECK, A.B. Desenhos: Representações de aves no ensino fundamental - anos finais, um estudo introdutório. V Encontro Regional Sul de Ensino de Biologia (EREBIO-SUL) IV Simpósio Latino Americano e Caribenho de Educação em Ciências do International Council of Associations for Science Education (ICASE). 2011.

VIGOSTSKY, L. A Formação Social da Mente: O desenvolvimento dos processos superiores. São Paulo, Martins Fontes, 1988.

WALLON, P., CAMBIER, A., ENGELHART, D., Le dessin de l'enfant. France: Press Universitaires de France. 1990.

WORTMANN, M. L. C. O uso do termo representação na educação em ciências e nos estudos culturais. Programa de Pós-Graduação. V.12 n.1: mar./2001[34].

Submetido em: 08 de janeiro de 2020.

Aprovado em: 13 de março de 2020. 